\title{
A Comparative Study of International Insurance Markets"
}

\author{
Wei Zheng ${ }^{\mathrm{a}, \mathrm{b}}$, Yongdong $\mathrm{Liu}^{\mathrm{c}}$ and Yiting Deng ${ }^{\mathrm{d}}$ \\ ${ }^{a}$ Department of Risk Management and Insurance, School of Economics, Peking University, Beijing, \\ China. \\ ${ }^{\mathrm{b}}$ China Centre for Insurance and Social Security Research (CCISSR), Peking University, Beijing 100871, \\ China. \\ ${ }^{\mathrm{c}}$ Centre for Chinese Agricultural Policy, Chinese Academy of Sciences, Beijing 100101, China. \\ ${ }^{\mathrm{d} C h i n a}$ Centre for Economic Research (CCER), Peking University, Beijing 100871, China.
}

By proposing the Benchmark Ratio of Insurance Penetration (BRIP) as a new paradigm for international insurance comparison, this paper makes a new assessment and comparison of insurance growth levels of certain countries as well as certain economic groups, and further discusses the policy implications. The main conclusions of this paper are as follows. First, it is necessary to have a new recognition of the international insurance growth pattern: the relative level of insurance growth in developed markets has declined as compared with that indicated by traditional indicators, and the relative level of insurance growth in developing markets has increased. The relative growth level of the insurance industry in developed markets is still higher than that in developing markets, but the insurance industry in emerging markets and Brazil, Russia, India and China (BRIC) is undergoing rapid development and has achieved a relatively high level. Second, when considering global expansion strategy, insurance companies should not only continue to consolidate market share in developed markets but also actively explore developing markets. In the meantime, insurance companies need to pay special attention to the fact that the relative insurance growth of emerging markets and BRIC has already reached a relatively high level. Although there is still significant potential for growth, the growth will mainly be driven by the ordinary economic factors, and the pattern of insurance growth would be expected to experience great changes. Third, the insurance industry policy for developing countries should focus on the adjustment and improvement of the pattern of growth instead of the quantitative increase in growth, so as to build a solid foundation for sustainable insurance growth in the long-term future. Fourth, the traditional paradigms are confined by certain limitations, so that we have to establish a more solid paradigm for international insurance comparison. By doing so, we can build a more reasonable

\footnotetext{
* A former version of this paper was awarded the "Shin Research Excellence Award" (2008) by The Geneva Association and the International Insurance Society (IIS), presented at the IIS 44th annual conference in Taipei in July 2008. We would like to thank The Geneva Association, IIS and Shin Fund, as well as the anonymous referees and judging committee for their valuable comments and advice. We are also grateful to Professor Gerry Dickinson from City University (U.K.), Professor Sun Qixiang from Peking University (China), Professor Yu Tong from University of Rhode Island (U.S.) and Professor Zou Hong from City University of Hong Kong for their helpful comments and suggestions. We thank Swiss Re (especially Mr. Clarence Wong) for data support and thank Prof. William Rabel from University of Alabama (U.S.) for his kind help in correcting. The usual disclaimer applies.
} 
foundation for international cooperation in insurance regulation and for relevant negotiation of international trade.

The Geneva Papers (2009) 34, 85-99. doi:10.1057/gpp.2008.37

Keywords: insurance industry; growth level; international comparison

\section{Introduction}

The international comparison of insurance growth is an issue of great importance against the background of globalisation. A reasonable evaluation of each country's 1 insurance growth level would not only help insurance companies with their global expansion strategy, and help governments to make industry policies, but also provide the basis for international cooperation of insurance regulation as well as related negotiation of international trade.

When comparing the insurance growth levels of two countries, people tend to confine the comparison to the insurance industry. However, the insurance industry is one of the economic segments, and its growth is to some degree endogenous to the development of the economy. This is to say, when discussing the growth level of a country's insurance industry, its stage of economic development cannot be neglected. An international insurance comparison, likewise, will make more sense only when it is based on the comparable "economic-adjusted insurance growth level".

In the existing literature on international insurance comparison, commonly used methods are "premium income method", "insurance density method" and "insurance penetration method". The premium income method measures the overall scale of the insurance market in each country. However, it fails to take into consideration the population factor, and thus cannot well represent the true level of insurance growth. The insurance density method (premium/population) measures the per capita premium by taking population into consideration, and often it will better reflect the true level of insurance growth of each country compared with the premium income method. However, it only considers the development of the insurance industry and neglects the economic development of the country; thus it fails to take into consideration the relationship between the insurance industry and the economy. The insurance penetration method (premium/GDP, or insurance density/GDP per capita) could be considered as an adjustment with economic factors added to the insurance density method. But it fails to reflect the reality that different stages of economic development are accompanied by different insurance penetrations. ${ }^{2}$ It is well known that countries differ significantly in population and economic growth level, so that none of the above three methods could be an ideal measurement of "insurance growth relative to economic growth".

This paper will propose a new method, Benchmark Ratio of Insurance Penetration (BRIP), for comparing insurance growth across different countries,

\footnotetext{
${ }^{1}$ Use of the term "country" in this paper refers to "country" or "region".

${ }^{2}$ It could be observed from Figure 1 that as a general rule, the insurance penetration will be higher when the GDP per capita is higher.
} 
which not only takes into account the overall scale of the insurance market of each country but also considers the population, economy and the relationship between the insurance penetration and the stage of economic development. By comparing the results obtained under this new method and those under the traditional methods, we can make some new judgements about international insurance growth.

The rest of the paper is organised as follows: the next section introduces the new method (BRIP) and the "insurance growth model" on which the calculation of the new indicator is based. The subsequent section compares the insurance growth level of certain countries and economic groups based on the new "BRIP" method and raises new judgements. The penultimate section further discusses the implications of the new judgements. The last section draws conclusions.

\section{New method: content and model}

In this section, we will first introduce a new method "BRIP", and then analyse the "insurance growth model" on which the calculation of the new indicator is based.

\section{The meaning of "BRIP"}

The core indicator of the new method is the "Benchmark Ratio of Insurance Penetration" or BRIP, which is a measure of the "benchmark-adjusted insurance growth level". Put more specifically, the BRIP evaluates the relative relationship between a country's insurance penetration and the world's average penetration at an economic level equal to the country's GDP per capita. If we define "the world average insurance penetration at the same economic level" as "benchmark penetration", a country's BRIP can be calculated as follows:

$$
B R I P=\frac{\text { actual penetration }}{\text { benchmark penetration }} \times 100 \%
$$

The denominator, "benchmark penetration", refers to "the world average insurance penetration at a country's economic level" and the numerator, "actual penetration", refers to a country's actual penetration.

As has been mentioned above, insurance density is an adjustment to premium income by adding the "population factor"; insurance penetration is an adjustment to insurance density by taking into account the "economic factor"; and BRIP is a "benchmark" adjustment to insurance penetration, with the key being to recognise the important rule that different stages of economic development are accompanied by different insurance penetrations. Therefore, the BRIP represents the comparable "economic-adjusted insurance growth level" and is a more reasonable indicator for the international comparison of insurance among countries than premium, insurance density and insurance penetration. 
The calculation of the BRIP of a country could be conducted following three steps. First, use an appropriate model to calculate the "benchmark penetration" for the country, which is the "world's average penetration at a country's economic level". Second, calculate this country's actual penetration. Third, divide the actual penetration by the benchmark penetration and obtain the value of BRIP.

The calculation of the "benchmark penetration" is an essential step in this process and it should be based on the "insurance growth model".

\section{Insurance growth model}

There are currently three major types of insurance growth models available. The first type is the simple linear model, the second is the logarithmic linear model and the third one is the logistic model. Each type has some advantages as well as limitations, but comparatively the logistic model is superior to the first two models for this research. ${ }^{3}$

Carter and Dickinson ${ }^{4}$ and Enz $^{5}$ developed a logistic model to depict the relationship between insurance penetration and GDP per capita. We label it as the "ordinary growth model". Using a large amount of historical data, we will estimate the growth of insurance or the "ordinary growth model".

The expression of the ordinary growth model is the following:

$$
Y=\frac{1}{C_{1}+C_{2} C_{3}^{X}}+\varepsilon
$$

where $Y$ is the insurance penetration, $X$ is the GDP per capita, $C_{1}, C_{2}$ and $C_{3}$ are three parameters, ${ }^{6}$ and $\varepsilon$ is the residual. ${ }^{7}$

This paper uses the data of 95 countries and regions over the past 28 years $(1980-$ 2007 ) as the sample. ${ }^{8}$ There are 2,143 observations in the life insurance sample, 2,162

${ }^{3}$ Refer to Zheng et al. (2008) for the detailed discussion on the model setting.

${ }^{4}$ Carter and Dickinson (1992).

${ }^{5}$ Enz (2000).

${ }^{6}$ Refer to Zheng et al. (2008) for the detailed discussion on the model setting and the description of the three parameters.

${ }^{7}$ Some researchers believe that insurance has some impacts on economic growth on the same period (e.g. Outreville, 1990; Soo, 1996; Webb et al., 2002; Arena, 2006), while others indicate that such an endogenous relationship does not really exist (e.g. Ward and Zurbruegg, 2000; Adams et al., 2005; Kugler and Ofoghi, 2005). Apparently, there is no consensus on the impact of insurance on economic growth on a short term. In order to deal with the potential endogeneity problem, we have tried to use one-period lagged GDP per capita as the regressor instead and the results are very close to our existing estimates. This implies that endogeneity is not a serious concern for our model. Therefore we accept the estimates obtained from the current model.

${ }^{8}$ The GDP, population and GDP per capita data of every country and region come from the National Accounts Main Aggregates Database which is provided by the United Nations. The data on total premium, life premium, non-life premium, total insurance penetration, life penetration and non-life penetration are taken from the Sigma database provided by Swiss Re. GDP per capita figures are at constant 1990 prices in U.S.\$. The penetration figures are the relative ratio (premium/GDP) and are not affected by the prices. Specifically, in the data used in this paper, the classification of life insurance and non-life insurance follows the tradition of the EU and OECD, in which health insurance and accident insurance are all in the catalogue of non-life insurance. 
Table 1 Summary statistics

\begin{tabular}{lccccc}
\hline Variables & Obs. & Mean & Std. dev. & Min & Max \\
\hline GDP per capita & 2,550 & 9,410 & 11,251 & 71 & 78,336 \\
Insurance penetration & 2,114 & $3.80 \%$ & $3.24 \%$ & $0.04 \%$ & $20.36 \%$ \\
Life penetration & 2,143 & $1.86 \%$ & $2.33 \%$ & $0.00 \%$ & $14.97 \%$ \\
Non-life penetration & 2,162 & $1.92 \%$ & $1.41 \%$ & $0.01 \%$ & $14.33 \%$ \\
\hline
\end{tabular}

Data resources: National Accounts Main Aggregates Database provided by the United Nations; the official website of National Statistical Bureau; the Sigma database provided by Swiss Re.

Note: GDP per capita is the 1990 U.S.\$.

Table 2 Estimates of the "ordinary growth model" of world insurance

\begin{tabular}{lrrr}
\hline & Life insurance & Non-life insurance & Insurance industry \\
\hline$C_{1}$ & $24.666(18.98)^{* * *}$ & $48.440(37.04)^{* * *}$ & $36.940(17.87)^{* * *}$ \\
$C_{2}$ & $105.034(12.87)^{* * *}$ & $34.755(47.70)^{* * *}$ & $14.171(26.75)^{* * *}$ \\
$C_{3}$ & $0.862(66.05)^{* * *}$ & $0.855(13.33)^{* * *}$ & $0.867(72.66)^{* * *}$ \\
$R^{2}$ & & & \\
Adjusted- $R^{2}$ & 0.5380 & 0.7115 & 0.7051 \\
Number of observations & 0.5374 & 0.7111 & 0.7047 \\
GDP per capita at the inflexion & 2,143 & 2,162 & 2,114 \\
(1990 U.S.\$) & 9,747 & 2,114 & 6,721 \\
Maximum income elasticity of premium & 1.744 & & 1.552 \\
GDP per capita at the maximum & 11,734 & 8,646 & 10,888 \\
elasticity (1990 U.S.\$) & & &
\end{tabular}

Note: Robust $t$-statistics is in parentheses. The term "***" means that the level of significance is 1 per cent.

observations in the non-life sample and 2,114 observations in the insurance sample. Table 1 shows the summary statistics of related variables; Table 2 shows the estimates of the ordinary growth model for world life insurance, non-life insurance and the insurance industry. Figure 1 depicts the regression curves of life insurance, non-life insurance and the insurance industry accordingly, which represent the term of $1 /\left(C_{1}+C_{2} C_{3}^{X}\right)$ in Eq. (2), the "benchmark penetration" under a certain per capita GDP.

As illustrated in Figure 1, under the ordinary growth model supported by the statistical tests, the regression curves of life insurance, non-life insurance and the insurance industry all resemble the shape of the letter " $S$ ", and this is the reason why the model is called "ordinary S-curve". As can be seen from the figure, insurance penetration (the ratio of the premium to the GDP) rises with GDP per capita, but different levels of GDP per capita are accompanied by different growth rates of insurance penetration. When the level of GDP per capita is low, the growth rate of insurance penetration is relatively slow. As GDP per capita increases, the growth rate of insurance penetration increases as well. However, after GDP per capita reaches a higher level, insurance penetration tends to plateau. This means, with the increase of GDP per capita, the growth rate of premium will exceed that of GDP per capita. The 


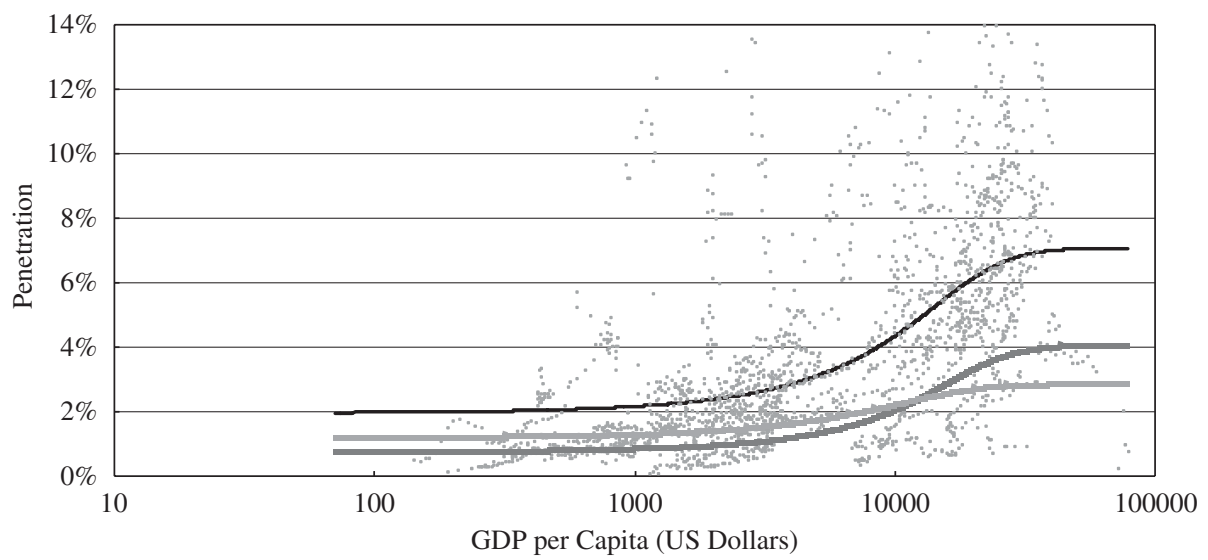

Real Insurance Penetration

— Non-Life Insurance Growth Curve _ _ Insurance Growth Curve

Life Insurance Growth Curve

Figure 1. Regression curves of the "ordinary growth model" of world insurance.

gap of the two growth rates is smaller when GDP per capita is low, and expands with the growth of GDP per capita, but will eventually narrow after a certain stage.

\section{Comparison of international insurance growth}

From what has been discussed above, we can see that the BRIP method is distinguished from the traditional methods of premium income, insurance density and insurance penetration. Correspondingly, such a difference makes the ranking results based on these various methods distinct. In this section, we will first compare the relevant indicators of 2007 for each country, then compare those for each economic group and later discuss the change of BRIP for each economic group.

\section{Comparison of relevant indicators for each country}

Table 3 presents the rankings of the BRIP, premium income, insurance density and insurance penetration for each country in 2007. As we can see, a country's ranking can vary significantly under different indicators.

Take the U.S. for instance. In 2007, its premium income, insurance density, insurance penetration and BRIP are respectively ranked 1st, 8th, 14th and 26th in the world. As is revealed from these numbers, although the premium of the U.S. is the largest in the world (1st), the insurance density (the premium per capita) is ranked lower (8th) due to the relatively large U.S. population. At the same time, the ranking of the insurance penetration (premium/GDP) is even lower (14th) due to the high economic development level. Furthermore, if taking into consideration the rule that "the benchmark insurance penetration will be higher when the GDP per capita is higher", the ranking of the BRIP descends further (26th). This means that, for the 
Table 3 Insurance industry rankings of 93 countries in 2007

\begin{tabular}{|c|c|c|c|c|c|c|c|c|c|}
\hline Country/region & Premium & Density & Penetration & $B R I P$ & Country/region & Premium & Density & Penetration & $B R I P$ \\
\hline United States $^{1 \mathrm{a}}$ & 1 & 8 & 14 & 26 & Ukraine $^{2}$ & 48 & 71 & 54 & 31 \\
\hline United Kingdom $^{1 \mathrm{a}}$ & 2 & 2 & 3 & 5 & Romania $^{2}$ & 49 & 63 & 70 & 59 \\
\hline $\operatorname{Japan}^{1 \mathrm{a}}$ & 3 & 14 & 11 & 23 & Slovenia $^{1}$ & 50 & 28 & 28 & 38 \\
\hline France $^{1 \mathrm{a}}$ & 4 & 6 & 10 & 16 & Slovakia $^{2}$ & 51 & 41 & 49 & 45 \\
\hline Germany $^{1 \mathrm{a}}$ & 5 & 18 & 24 & 50 & Saudi Arabia ${ }^{2}$ & 52 & 68 & 92 & 90 \\
\hline Italy $^{1 \mathrm{a}}$ & 6 & 22 & 25 & 49 & Morocco $^{2 b}$ & 53 & 73 & 46 & 19 \\
\hline South Korea $^{1}$ & 7 & 21 & 6 & 7 & Philippines $^{2 b}$ & 54 & 86 & 77 & 67 \\
\hline Netherlands ${ }^{1}$ & 8 & 3 & 5 & 9 & Croatia $^{2}$ & 55 & 44 & 47 & 51 \\
\hline Canada $^{1 \mathrm{a}}$ & 9 & 15 & 22 & 41 & Kazakhstan $^{2}$ & 56 & 70 & 80 & 76 \\
\hline China $^{2 b c}$ & 10 & 72 & 52 & 29 & Peru $^{2 b}$ & 57 & 82 & 82 & 80 \\
\hline Spain $^{1}$ & 11 & 25 & 30 & 55 & Trinidad and Tobago ${ }^{2}$ & 58 & 33 & 26 & 21 \\
\hline Australia $^{1}$ & 12 & 16 & 23 & 44 & Egypt $^{2 b}$ & 59 & 89 & 86 & 82 \\
\hline Ireland $^{1}$ & 13 & 1 & 8 & 14 & Pakistan $^{2 b}$ & 60 & 91 & 88 & 84 \\
\hline Taiwan $^{1}$ & 14 & 19 & 2 & 4 & Bulgaria $^{2}$ & 61 & 62 & 55 & 46 \\
\hline India $2 \mathrm{bc}$ & 15 & 81 & 33 & 8 & Vietnam $^{2}$ & 62 & 90 & 78 & 62 \\
\hline Belgium $^{1}$ & 16 & 7 & 12 & 22 & Angola $^{2}$ & 63 & 78 & 79 & 72 \\
\hline Switzerland $^{1}$ & 17 & 4 & 9 & 20 & Cyprus $^{1}$ & 64 & 31 & 37 & 57 \\
\hline South Africa ${ }^{2 b}$ & 18 & 32 & 4 & 2 & Nigeria $^{2}$ & 65 & 92 & 90 & 86 \\
\hline Brazil $^{2 b c}$ & 19 & 55 & 51 & 43 & Lithuania $^{2}$ & 66 & 51 & 64 & 61 \\
\hline Sweden $^{1}$ & 20 & 11 & 21 & 39 & Lebanon $^{2}$ & 67 & 56 & 44 & 18 \\
\hline Russia $^{2 b c}$ & 21 & 53 & 60 & 56 & Kuwait $^{2}$ & 68 & 50 & 91 & 92 \\
\hline Denmark $^{1}$ & 22 & 5 & 13 & 28 & Kenya $^{2}$ & 69 & 88 & 58 & 30 \\
\hline Hong Kong $^{1}$ & 23 & 13 & 7 & 11 & Algeria $^{2}$ & 70 & 87 & 93 & 89 \\
\hline Austria $^{1}$ & 24 & 20 & 27 & 54 & Tunisia $^{2}$ & 71 & 75 & 65 & 58 \\
\hline Finland $^{1}$ & 25 & 9 & 17 & 32 & Ecuador $^{2}$ & 72 & 79 & 75 & 68 \\
\hline
\end{tabular}


Table 3 continued

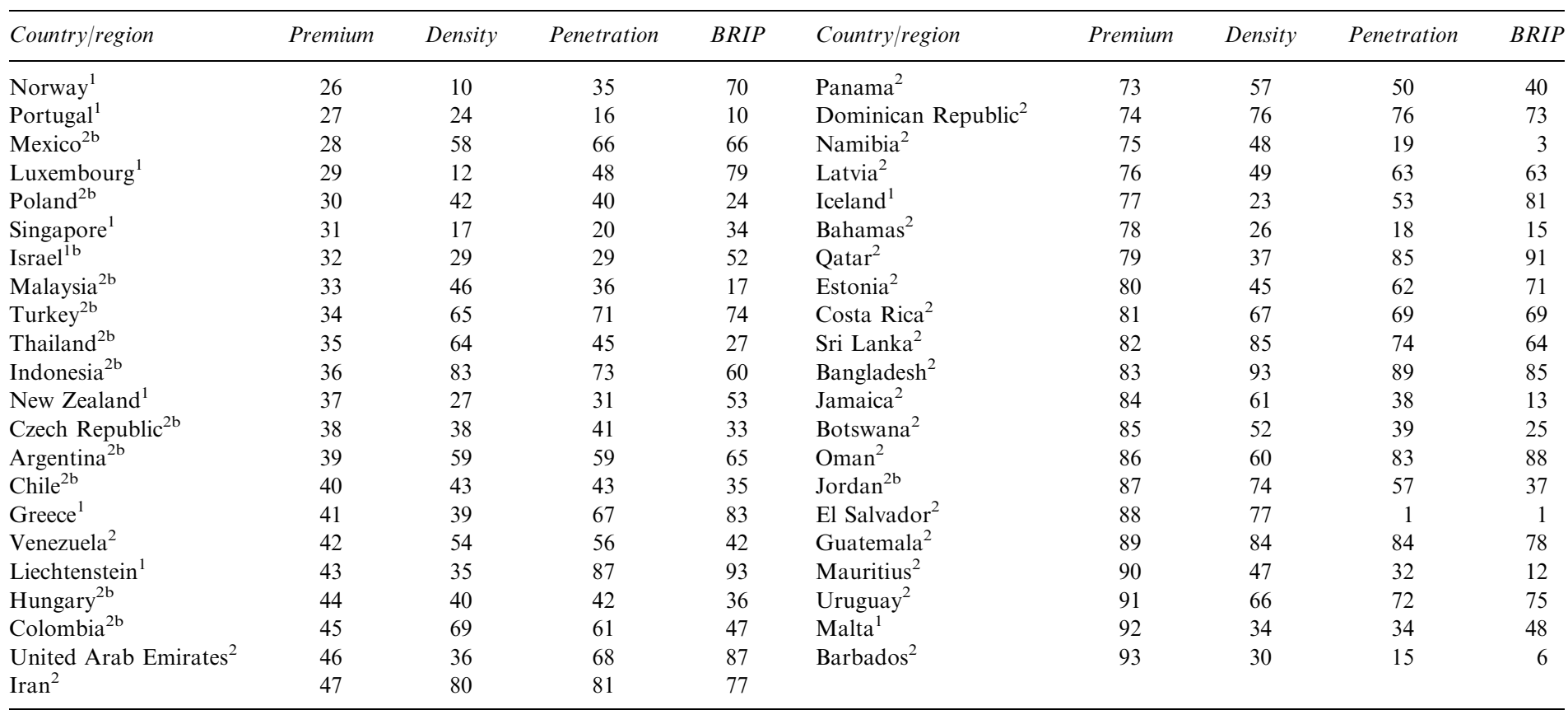

Data resources: National Accounts Main Aggregates Database provided by the United Nations; the official website of National Statistical Bureau; the Sigma database provided by Swiss Re; calculation by author.

Note: "1" represents developed country or region. "2" represents developing country or region. "a" represents G7 country. "b" represents new emerging country or region. "c" represents BRIC country. 
U.S., the ranking of the BRIP declines compared with the rankings of those traditional indicators like premium income, insurance density, as well as insurance penetration. Remarkably, many developed countries such as Japan, U.K., France and Germany share similar characteristics.

Take China as another example. In 2007, its premium income, insurance density, insurance penetration and BRIP are respectively ranked 10th, 72nd, 52nd and 29th in the world. As is revealed from these numbers, although the premium of China is among the largest in the world (10th), the ranking of China's insurance density (the premium per capita) is significantly lower (72nd) due to the very large population. The insurance penetration is ranked higher than the insurance density (52nd) due to the relatively low economic development level. Taking into consideration the rule that "the benchmark penetration will be lower when GDP per capita is lower", the ranking of the BRIP rises further (29th). This means that, for China, the ranking of the BRIP rises compared with the rankings of those traditional indicators like insurance density and insurance penetration. Remarkably, many emerging countries such as Brazil and India share similar characteristics.

\section{Comparison of related indicators for each economic group}

The above discussion reveals detailed information about each country's relevant indicators. In order to view more clearly the differences among different economic groups, we categorise the countries into two major groups: "developed markets" and "developing markets". In addition, we separate out "G7" from the developed markets, "emerging markets" from the developing markets, and also "BRIC" (Brazil, Russia, India and China) from the emerging markets.

Table 4 presents the average BRIP, average premium income, average insurance density, average insurance penetration and average per capita GDP for each economic group in 2007. Table 5 further presents the average ranking percentile of each group.

Table 4 The general situation of the insurance industry by economic group in 2007

\begin{tabular}{lrccccc}
\hline & Obs. & $\begin{array}{c}\text { GDP } \\
\text { per capita } \\
\text { (U.S.\$) }\end{array}$ & $\begin{array}{c}\text { Average } \\
\text { premium income } \\
\text { (million U.S.\$) }\end{array}$ & $\begin{array}{c}\text { Average } \\
\text { insurance } \\
\text { density (U.S.\$) }\end{array}$ & $\begin{array}{c}\text { Average insurance } \\
\text { penetration } \\
\text { (percent) }\end{array}$ & $\begin{array}{c}\text { Average } \\
\text { BRIP }\end{array}$ \\
\hline $\begin{array}{l}\text { Developed markets } \\
\text { G7 }\end{array}$ & 32 & 44,047 & 114,031 & 3,107 & 7.68 & 1.23 \\
Developing markets & 7 & 40,575 & 407,520 & 3,815 & 9.22 & 1.38 \\
$\quad$ Emerging markets & 18 & 5,796 & 6,637 & 237 & 3.08 & 1.12 \\
$\quad$ BRIC & 4 & 4,871 & 53,873 & 207 & 3.22 & 1.21 \\
World average & 93 & 20,925 & 43,590 & 1,224 & 3.23 & 1.33 \\
\hline
\end{tabular}

Data resources: National Accounts Main Aggregates Database provided by the United Nations; the official website of National Statistical Bureau; the Sigma database provided by Swiss Re; calculation by author. Note: The U.S.\$ is the 2007 price. 
Table 5 Average percentile rankings of the insurance industry by economic group in 2007 (per cent)

\begin{tabular}{lcccc}
\hline & Premium income & Insurance density & Insurance penetration & BRIP \\
\hline Developed markets & 27 & 18 & 26 & 42 \\
G7 & 5 & 13 & 17 & 32 \\
Developing Markets & 63 & & 63 & 55 \\
$\quad$ Emerging markets & 42 & 67 & 59 & 48 \\
$\quad$ BRIC & 17 & 68 & 53 & 37 \\
World average & 51 & 70 & 51 & 51 \\
\hline
\end{tabular}

Data resources: National Accounts Main Aggregates Database provided by the United Nations; the official website of National Statistical Bureau; the Sigma database provided by Swiss Re; calculation by author.

Note: There are 93 countries or regions being ranked.

We can see from Table 5 that, in terms of average ranking, the developed markets and the developing markets present different characteristics. In the order of insurance density, insurance penetration and BRIP, the average percentiles of developed markets are respectively 18, 26 and 42 per cent, which are decreasing in turn. However, the average percentiles of developing markets are respectively 67, 63 and 55 per cent, which are increasing in order. The G7 group has similar characteristics to the developed markets, and the emerging markets as well as BRIC have characteristics similar to those of the developing markets. It is worth mentioning, however, that the increasing trend in ranking is more obvious in emerging markets than in developing markets, and much more significant in BRIC than in emerging markets.

Measured by insurance density, the average ranking of developed markets (18 per cent) is markedly ahead of that of developing markets (67 per cent), with a difference of 49 percentage points. Measured by insurance penetration, the average ranking of developed markets ( 26 per cent) is also ahead of that of developing markets (63 per cent), with a smaller gap of 37 percentage points. Measured by BRIP, the disparity between the average ranking of developed markets (42 per cent) and that of developing markets ( 55 per cent) decreases further, with a gap of 13 percentage points. The average ranking of emerging markets ( 48 per cent) is quite close to that of developed markets, with a lag of only 6 percentage points, and that of BRIC (37 per cent) is even ahead of that of developed markets by 5 per cent. Meanwhile, the G7 group is still at the top (32 per cent).

As mentioned above, the BRIP represents the "economic-adjusted insurance growth level" and is thus a more reasonable indicator for international insurance comparison. Therefore, the BRIP is more convincing as a measurement of insurance growth than traditional indicators. As the new indicator BRIP implies, the ranking of developed markets declines remarkably, while that of the developing markets increases remarkably, so that the comparative advantage of developed markets over developing markets decreases. Furthermore, the performances of emerging markets in developing markets, especially BRIC, are outstanding. 
In summation, as is revealed by the analysis above, we should have a new recognition of the international insurance growth pattern: under the new indicator, BRIP, the relative level of insurance growth in developed markets in 2007 has declined as compared with that indicated by traditional indicators, and the relative level of insurance growth in developing markets has increased, with the emerging markets and BRIC outperforming.

\section{Comparison of BRIP in different periods}

From what we have discussed above, we can see that the BRIP represents the "economic-adjusted insurance growth level", and is a more reasonable indicator for international insurance comparison. Therefore, besides comparing the ranking of BRIP with that of traditional indicators in 2007 (the latest available data), we have to pay special attention to the change in BRIP for different economic groups over the past decades, in order to reveal the overall tendency of insurance growth in a relative long term.

Figure 2 depicts the BRIP of the world average, developed markets average, developing markets average, G7 average, emerging markets average and BRIC average during 1980-2007. There are several facts that can be obtained from the figure. First, the BRIP of developed markets is higher than the BRIP of developing markets every year, and the world average level is in between. Second, the BRIP of the G7 group is higher than that of other groups, and is always the highest. Third, the BRIPs of the emerging markets and BRIC are undergoing rapid increase, gradually overtaking the BRIP of the developing markets' average level as well as the world average level starting from relatively low levels in the 1980s, and are even catching up

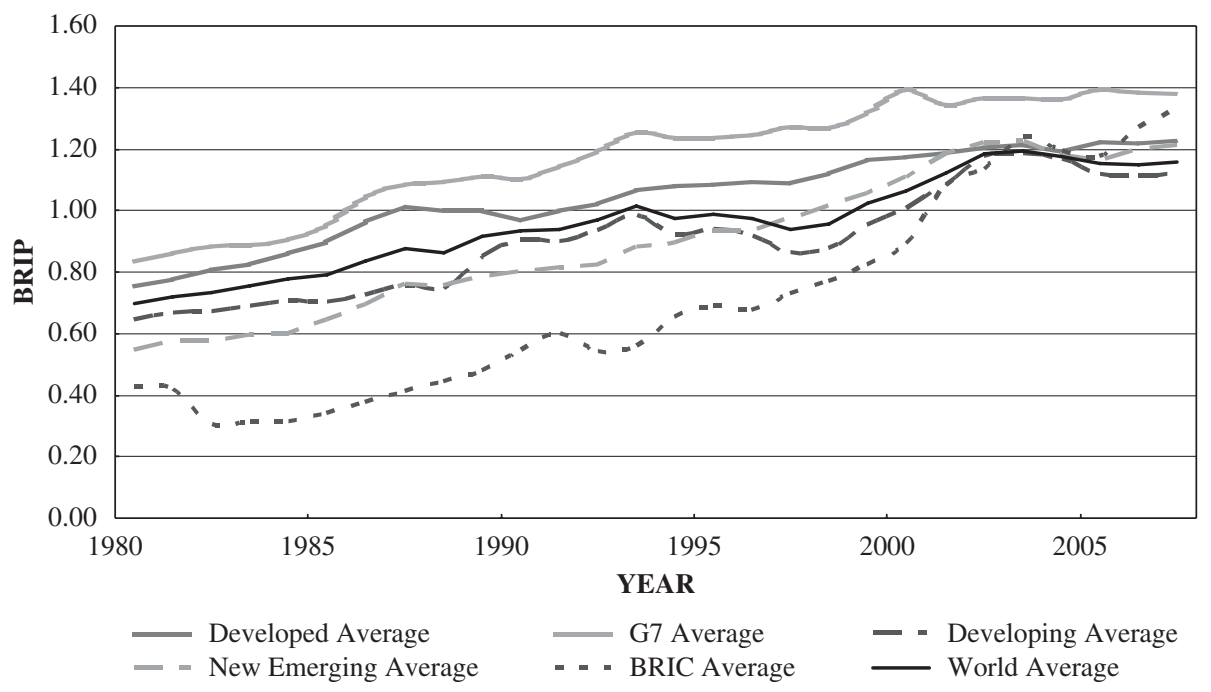

Figure 2. The BRIP curve for different economic groups during 1980-2007. 
with the BRIP of developed markets. The insurance growth of BRIC since the beginning of the 21 st century is especially rapid.

That is to say, under the new indicator, over the past more than two decades, the relative growth level of the insurance industry in developed markets (relative to their economic level) is still higher than that in developing markets. However, the insurance industries in emerging markets and BRIC are undergoing rapid development, and have reached a relatively high level.

From what has been discussed in this section, we can see that the international insurance growth pattern has changed. The relative level of insurance growth in developed markets has declined as compared with that indicated by traditional indicators, and that in developing markets has increased. Meanwhile, the relative growth level of insurance industry in developed markets is still higher than that in developing markets. However, the insurance industries in emerging markets and BRIC are undergoing rapid development and have reached a relatively high level.

\section{Discussion on policy implications}

In the above sections, we have discussed the new method of "BRIP", and assessed and compared international insurance growth with this new method. The comparison has led to some new judgements and conclusions. An important idea we have been keeping throughout our analysis is that the insurance industry is one of the economic segments, and its growth is to some degree endogenous to the development of the economy. This means that, when discussing the growth level of a country's insurance industry, the economic development level cannot be neglected. An international insurance comparison, likewise, will make more sense only when it is based on the comparable "economic-adjusted insurance growth level". The next question is: what are the implications of these analyses? As far as we are concerned, this kind of analysis would not only help insurance companies with their global expansion strategy, but would also help governments make industry policies, provide the basis for international cooperation in insurance regulation and provide information relevant to international trade negotiation.

Consider first the implication for strategic global expansion of insurance companies. When an insurance company declares a global expansion strategy, one of the factors it should take into consideration is a reasonable judgement about each country's insurance growth level. However, judgement based on traditional indicators such as premium income, insurance density and insurance penetration has obvious limitations, while the application of the new indicator "BRIP" can effectively make up for these limitations and reveal a new "insurance growth level". According to the above analysis, the relative level of insurance growth in developed markets has declined as compared with that indicated by traditional indicators, and that in developing markets has increased. Meanwhile, generally speaking, the relative growth level of the insurance industry in developed markets is still higher than that in developing markets, but the insurance industries in emerging markets and BRIC are undergoing rapid development, and have reached a relatively high level. Therefore, we can anticipate the following implications for the global expansion strategy of insurance companies. On 
the one hand, companies should continue to consolidate their market share in developed markets. On the other hand, they should actively explore developing markets. In the meantime, insurance companies should be aware that the relative insurance growth level of emerging markets and BRIC has reached a relatively high level. Although there is still great potential for growth, the growth will mainly be driven by the ordinary economic factors and the pattern of insurance growth would be expected to experience great changes.

Second, consider the implications for government insurance industry policies. In an era of globalisation, the establishment of one country's insurance industry policies is often related to that country's relative insurance growth level. The international comparison of insurance growth should not merely be a simple comparison between the insurance industries of different countries, but also be a comparison of benchmarkadjusted insurance growth levels. This study provides such a comparison that could be applied for policy making. According to the ordinary growth model, Figure 3 depicts the change of the income elasticity of premium (i.e. the ratio of change in the growth rate of premiums and change in the growth rate of per capita GDP). We can see from this figure that the income elasticity of premium keeps increasing when per capita GDP is between U.S.\$1,000 and U.S.\$10,000, reaching the highest level of 1.55 when per capita GDP is U.S.\$ 10,000, and then it gradually decreases. Generally speaking, therefore, when GDP per capita is between U.S.\$ 1,000 and U.S.\$ 10,000, as GDP per capita increases, premium per capita will experience an accelerated growth. As a result, this period is quite crucial to the growth in insurance. Thus we may obtain an important implication for government insurance industry policies: the relative insurance growth level of developing countries is not as low as the traditional indicators imply, and that of emerging markets and BRIC has even reached quite a high level. Therefore, the insurance industry policy for developing countries should focus on the adjustment and improvement of growth pattern instead of quantitative increases, in order to build a solid foundation for sustainable insurance growth in the long term.

Last, consider the implications for international cooperation on insurance regulation and relevant negotiation of international trade. Accurate assessment of

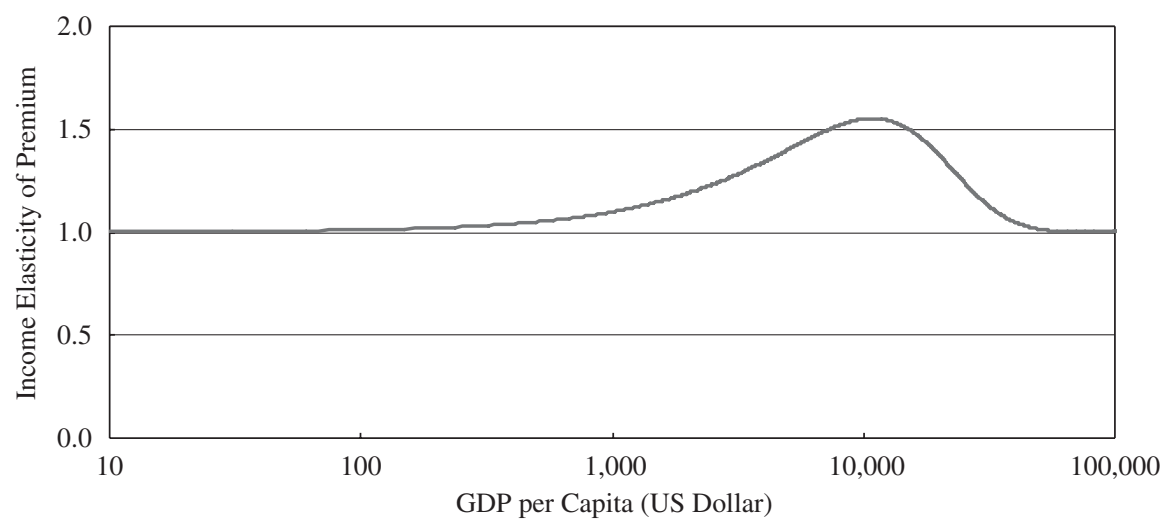

Figure 3. Income elasticity of premiums. 
the relative insurance growth level is important for fulfilling both of these two tasks. For instance, obviously, if the insurance growth level cannot be estimated accurately, international cooperation in insurance regulation may be hampered. For another example, in WTO and other negotiations, the openness of financial markets, including that of the insurance market, is always a matter of great importance. One of the major reasons why developed countries demand that developing countries open their insurance market is that the insurance growth level is too low in developing countries. However, following the above analysis, the relative insurance growth level of developing countries is not as low as revealed by the traditional indicators. The implication is therefore: the traditional paradigms are confined by certain limitations, so we have to establish a more solid paradigm for an international insurance comparison. By doing so, we can build a more reasonable foundation for international cooperation on insurance regulation and relevant negotiation of international trade.

\section{Conclusion}

By proposing BRIP as a new method for an international insurance comparison, this paper makes a new assessment and a new comparison of insurance growth levels of certain countries as well as certain economic groups, and further discusses the policy implications.

The main conclusions of this paper are as follows:

First, we need to have a new recognition of the international insurance growth pattern: the relative level of insurance growth in developed markets has declined as compared with that indicated by traditional indicators, and that in developing markets has increased. The relative growth level of the insurance industry in developed markets is still higher than that in developing markets, but the insurance industry in emerging markets and BRIC is undergoing rapid development and has achieved a relatively high level.

Second, when considering the global expansion strategy, the insurance companies should not only continue to consolidate market share in developed markets but also actively explore developing markets. In the meantime, the insurance companies have to become aware that the relative insurance growth of emerging markets and BRIC has already reached a relatively high level. Although there is still high potential for growth, the growth will mainly be driven by the ordinary economic factors, and the pattern of insurance growth would be expected to experience great changes.

Third, the insurance industry policy for developing countries should focus on the adjustment and improvement of the growth pattern instead of quantitative increases, in order to build a solid foundation for sustainable insurance growth in the long term.

Fourth, the traditional paradigms are confined by certain limitations, so we have to establish a more solid paradigm for an international insurance comparison. By doing so, we can build a more reasonable foundation for international cooperation on insurance regulation and relevant negotiation of international trade.

There are, to be sure, still many relevant researches worth doing in this area. This paper mainly studies the international comparison of the insurance "growth level" for different countries. Follow-up researches could pay attention to the comparison of insurance "growth structures", and further discuss the role of economic and institutional factors in insurance growth. 


\section{References}

Adams, M., Andersson, J. and Lindmark, M. (2005) The historical relation between banking, insurance, and economic growth in Sweden: 1830 to 1998, Norwegian School of Economics Working Paper.

Arena, M. (2006) Does insurance market activity promote economic growth? A cross-country study for industrialized and developing countries, World Bank Policy Research Working Paper 4098, December.

Carter, R.L. and Dickinson, G.M. (1992) Obstacles to the Liberalization of Trade in Insurance, London: Harvester Wheatsheaf, pp. 175-188.

Enz, R. (2000) 'The S-curve relation between per-capita income and insurance penetration', Geneva Papers on Risk and Insurance 25(3): 396-406.

Kugler, M. and Ofoghi, R. (2005) Does insurance promote economic growth? Evidence from the U.K., University of Southampton Working Paper.

Outreville, J.F. (1990) 'The economic significance of insurance markets in developing countries', Journal of Risk and Insurance 57(3): 487-498.

Soo, H.H. (1996) 'Life insurance and economic growth: Theoretical and empirical investigation. University of Nebraska Dissertation.

Ward, D. and Zurbruegg, R. (2000) 'Does insurance promote economic growth? Evidence from OECD countries', Journal of Risk and Insurance 67(4): 489-506.

Webb, I., Grace, M.F. and Skipper, H.D. (2002) The effect of banking and insurance on the growth of capital and output. Centre for Risk Management and Insurance Working Paper 02.

Zheng, W., Liu, Y. and Dickinson, G. (2008) 'The Chinese insurance market: Estimating its long-term growth and size', Geneva Papers on Risk and Insurance 33: 489-506.

\section{About the Authors}

Wei Zheng is Associate Professor and Vice Chair of the Department of Risk Management and Insurance at the School of Economics, Peking University, Beijing China. He is also Secretary General of the China Centre for Insurance and Social Security Research (CCISSR), Peking University, a member of Board of Directors of Insurance Institute of China (IIC) and a member of the Board of Governors of Asia-Pacific Risk and Insurance Association (APRIA).

Yongdong Liu is a graduate student of the Centre for Chinese Agricultural Policy in Chinese Academy of Science, Beijing, China. He holds a B.A. in Economics from the Department of Risk Management and Insurance at the School of Economics and a B.Sc. in Statistics from the School of Mathematical Sciences, Peking University, Beijing, China.

Yiting Deng is a graduate student at the China Centre for Economic Research in Peking University, Beijing, China. She holds a B.A. in Economics from the Department of Finance, the School of Economics, Peking University and a B.Sc. in Statistics from the School of Mathematical Sciences, Peking University. 